\title{
Maxime Du Camp, Expédition des Deux-Siciles.
} Souvenirs personnels

\section{Paola Labadessa}

\section{(2) OpenEdition}

\section{Journals}

\section{Edizione digitale}

URL: http://journals.openedition.org/studifrancesi/2225

DOI: $10.4000 /$ studifrancesi.2225

ISSN: 2421-5856

\section{Editore}

Rosenberg \& Sellier

\section{Edizione cartacea}

Data di pubblicazione: 1 aprile 2014

Paginazione: $172-173$

ISSN: 0039-2944

\section{Notizia bibliografica digitale}

Paola Labadessa, « Maxime Du Camp, Expédition des Deux-Siciles. Souvenirs personnels », Studi Francesi

[Online], 172 (LVIII | I) | 2014, online dal 01 avril 2014, consultato il 18 septembre 2020. URL : http:// journals.openedition.org/studifrancesi/2225 ; DOI : https://doi.org/10.4000/studifrancesi.2225

Questo documento è stato generato automaticamente il 18 settembre 2020.

\section{(c) $(7)$}

Studi Francesi è distribuita con Licenza Creative Commons Attribuzione - Non commerciale - Non opere derivate 4.0 Internazionale. 


\title{
Maxime Du Camp, Expédition des Deux-Siciles. Souvenirs personnels
}

\author{
Paola Labadessa
}

\section{NOTIZIA}

MAXIME DU CAMP, Expédition des Deux-Siciles. Souvenirs personnels (1861), edizione integrale a cura di Maria Gabriella ADAMO, Moncalieri, C.I.R.V.I., 2011, pp. 433.

1 Quando nei primi giorni di agosto giunse a Genova per imbarcarsi, la città aveva «un aspect étrange; elle semblait avoir la fièvre, la fièvre rouge». Chi la descrive è Maxime Du Camp, volontario, al pari di numerosi cronisti e viaggiatori stranieri, al seguito della spedizione dei Mille.

2 Il filone della letteratura garibaldina, recentemente rinvigorita da nuovi e interessanti studi pubblicati in occasione del Centocinquantenario dell'Unità d'Italia e che, a ben ragione, può dirsi costituire una sezione della vasta letteratura odeporica, si arricchisce della versione integrale dell'Expédition des Deux-Siciles di Maxime Du Camp, in una nuova edizione critica a cura di Maria Gabriella Adamo, con prefazione di Emanuele Kanceff, per la collana «Biblioteca del Viaggio in Italia» del Centro Interuniversitario di Ricerche sul Viaggio in Italia da lui diretto.

3 Il testo, che nel rispetto ortografico e linguistico dell'originale riprende la versione stampata nel 1861 a Parigi presso Bourdillat-Librairie Nouvelle, ripercorre, nei tre Livres che compongono l'opera, secondo la suddivisione già operata dall'autore ( $\mathrm{La}$ Sicile, Les Calabres, Naples et les avant-postes de Capoue), l'esaltante esperienza personale dello scrittore nelle Due Sicilie: «j'ai écrit ce que j'ai vu, rien de plus mais rien de moins, et je puis dire, sans pécher par excès d'amour-propre, que si ce livre a un mérite c'est celui de la sincérité» (Avertissement, p. 133).

4 Un poderoso ed approfondito saggio introduttivo di M. G. Adamo, strutturato in più parti e corredato da note dettagliate, apre l'opera rendendola fruibile anche ai non francofoni. L'analisi, supportata da attenti confronti e riferimenti, illustra il contesto 
storico e ideologico, oscillante tra le «ceneri romantiche» e «la nuova età positivista del Progresso e della Scienza», in cui maturano l'esperienza umana e letteraria dello scrittore parigino e i suoi rapporti con l'Italia, risalenti al primo viaggio del '44. La genesi dell'Expédition, oltre che nel vissuto culturale dell'autore degli Chants modernes e delle Convictions, è spiegata sia nell'ambito della questione italiana, del messianismo europeo e delle utopie sansimoniane che nel panorama della produzione garibaldina, già di indubbio successo in Francia e costellata da nomi quali quelli di Dumas padre, Louise Colet, La Varenne, La Bedollière (e, su altro versante, di Marc Monnier). Inoltre, va segnalata l'accurata ricostruzione della composizione dell'opera, basata su un Cahier contenuto nel Ms. 3723 conservato presso la Bibliothèque de l'Institut di Parigi, contenente in particolare una serie di articoli di Du Camp apparsi anonimi su L'Opinion Nationale in quei mesi del 1860 e alcune sue lettres scritte da Napoli. Ne risultano rilevate anche le varianti rispetto alla versione pubblicata all'inizio del ' 61 sulla «Revue des deux mondes».

Opera in cui «narrazione e saggio si alternano e si equilibrano», documento storico nel quale nomi, luoghi, episodi che hanno contribuito a una pagina fondamentale, seppure ancor oggi discussa, della nostra storia rivivono attraverso una scrittura realistica e suggestiva, l'Expédition risulta al contempo resoconto di un 'viaggio' nel regno borbonico da parte di un volontario che, tra i viaggiatori al Sud, «è forse quello che ne trasse l'esperienza più privilegiata, travalicante i limiti del consueto se pur avventuroso grand tour ottocentesco», avendo egli anche realizzato a piedi e non per mare, a differenza di molti altri, il percorso dalla Sicilia a Napoli. La situazione delle Deux-Siciles fra bellezza, decadenza civile e grandi potenzialità è quindi esaminata anche nel quadro della letteratura di viaggio al Sud, mettendo in rilievo i connotati peculiari di un testo dove si incrociano cronaca, riflessione storica, mito e, insieme, il diario personale di una straordinaria avventura che coinvolge una nuova consapevolezza esistenziale.

Una parte del saggio introduttivo è rivolta all'analisi delle forme linguistiche e delle tecniche di stile di un'opera che è anche «testimonianza della situazione della lingua francese» nella seconda metà del XIX secolo, "passata dalle intemperanze romantiche alle exploitations lessicali dei Realisti», con puntuali considerazioni sul lessico composito e l'individuazione di un duplice registro di scrittura, ora descrittivo, ora lirico-oratorio.

7 Un consistente apparato di note al testo, in aggiunta alle note originarie di Du Camp, mantenute a piè di pagina, come pure l'estesa bibliografia finale, efficacemente suddivisa per tematiche tra opere di argomento generale a carattere storico-letterario e opere specifiche, ne fanno un'edizione di riferimento.

8 Arricchita da numerose illustrazioni fuori testo sullimpresa garibaldina del 1860, l'opera risulta impreziosita dall'inserimento di alcuni documenti e, soprattutto, di fotografie originali rinvenute nel manoscritto. 